\title{
An investigation of magnet effect via overnight returns: the Malaysian case
}

\author{
Imtiaz Sifat and Azhar Mohamad \\ Department of Finance, International Islamic University Malaysia, \\ Kuala Lumpur, Malaysia, and \\ Zarinah Hamid \\ Department of Economics, International Islamic University Malaysia, \\ Kuala Lumpur, Malaysia
}

\begin{abstract}
Purpose - Magnet effect entails a hypothesis in market microstructure entailing a systemic likelihood of prices being sucked toward the theoretical threshold. The purpose of this paper is to investigate the existence of magnet effect in Bursa Malaysia via overnight returns.

Design/methodology/approach - This study investigates the existence of magnet effect via overnight returns in Bursa Malaysia by utilizing historical daily price data from 1994 to 2017 by probabilistic regression approaches. The authors divide the study period into three distinct regimes based on regulatory limit mechanisms. Findings - Based on demarcated regimes, the authors find evidence of magnet effect in Bursa Malaysia throughout all regimes, with a heightened magnitude detected between 2002 and 2013. Moreover, upper limit scenarios exhibit a greater propensity for magnet effect. The authors end the paper with implications of the findings for portfolio managers, intraday traders, and policymakers.
\end{abstract}

Originality/value - The research is the first of its kind in attempting to measure the magnet effect in Malaysia via overnight jumps.

Keywords ASEAN, Magnet effect, Circuit breakers, Price limits, Bursa Malaysia

Paper type Research paper

\section{Introduction}

Many stock exchanges around the world employ price limits in a bid to ameliorate unwanted (transitory) volatility, prevent illiquidity, and allay panic. Whether limits succeed in achieving this is disputed due to scant and conflicting empirical evidence. Price limits' proponents invoke the "cooling-off" hypothesis coined by Ma et al. (1989) arguing limits dissuade speculative overreactions, panic, noise trading, and price manipulation. Their adversaries claim interruptions arising out of price limits signal a disequilibrium; stock-wise or marketwise (Fama, 1989) - likely due to order imbalance or impending news announcement. Aside from evidence of trading interference and volatility persistence, some studies show evidence of limits as a self-fulfilling prophesy, whereby trading activity is sucked toward the limit by its very existence (Tooma, 2011; Wong et al., 2009, 2016). This, phenomenon, pioneered by Subrahmanyam (1994), is known as the magnet effect. Its opposite - the repellant effect - has been documented by Arak and Cook (1997) in US treasury bond futures and Hall and Kofman (2001) in five agricultural futures contracts in Chicago Board of Trade. However, empirical findings from futures markets are not generalizable for equities, since derivatives are known

JEL Classification — D43, D47, D53, G14, G41

(C) Imtiaz Sifat, Azhar Mohamad and Zarinah Hamid. Published in Journal of Capital Markets Studies. Published by Emerald Publishing Limited. This article is published under the Creative Commons Attribution (CC BY 4.0) licence. Anyone may reproduce, distribute, translate and create derivative works of this article (for both commercial and non-commercial purposes), subject to full attribution to the original publication and authors. The full terms of this licence may be seen at http://creativecommons.org/licences/by/4.0/legalcode

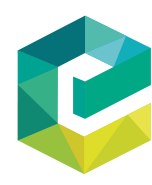

Journal of Capital Markets Studies Vol. 2 No. 2,2018 pp. 121-135 2514-4774 DOI 10.1108/JCMS-04-2018-0012 
JCMS

2,2

to have close substitute contracts. For equities, Abad and Pascual (2007) and Huang et al. (2001) find evidence against magnet effect in Spanish and Taiwanese stock exchanges, respectively.

Empirical findings on the magnet effect further fuel the broader controversy surrounding price limits' efficacy, especially for emerging markets, which not only suffer from ineffective regulation, weak governance, frequent market manipulation, and lax enforcement, but also incur higher volatility compared to advanced markets (Sifat and Mohamad, 2018a). In case of Malaysia, our empirical venue, the issue is more peculiar and pronounced due to the exchange's practice of a very wide price limit: \pm 30 percent since 1989 . Although this band has been complemented with some caveats, till now the limit is unchanged. With regards to the magnitude of a price limit, Kim (2001) points out that in markets with a tighter band does not necessarily result translate to efficiency. Thus, considering Malaysia's limit width and lack of prior empirical attempts, Bursa Malaysia emerges as an attractive laboratory for testing the magnet effect of price limits.

This paper is organized as follows. First, we introduce our empirical setting, Bursa Malaysia. Then we describe our data, sampling, and study design. Thereafter, we discuss the preliminary results based on 150 actively traded stocks, and conclude the paper by discussing the implication of findings.

\section{Review of literature}

\subsection{Historical backdrop}

Research on circuit breaker as sparse prior to Brady Commission's 1988 report following a regulatory bid to thwart market crashes. Prior to that, of note was Brennan's (1986) conjecture that limits can serve a quasi-margin purpose to enforce contract compliance in futures markets. Following the 1987 crash, Kyle (1988), Lehmann (1989), and Moser engaged in theoretical discourses on whether limits could be a good idea. While empirical efforts were understandably scarce at that stage, works of these financial economists laid much of the platform for future experts to build upon. Among the premier discussants in the 1990s, Madhavan and Subrahmanyam, in unrelated papers, hinted at the possibility that limiting mechanisms, by design, invite the contingency of traders fearing being locked out of a trade or open position. Thereafter, more researchers began getting interested in the magnet effect.

\subsection{Theoretical research}

Earliest theoreticians hypothesized that whenever faced with an imminent limit hit, traders would attempt to minimize their perceived fear by hastening orders, which, in turn, exacerbate the existing volatility leading to realization of the circuit breaker trigger. Based on Lehmann's (1989) predictions, Subrahmanyam (1994) formalized this hypothesis as the "magnet effect." His model postulates that rule-based trading interruptions motivate uninformed investors to rush trades in a frenzied way, which elevates ex ante volatility as price approaches the limit. In a later paper, Subrahmanyam (1995), furthermore, hypothesized that when the possibility of a limit-hit appears realistic, informed traders would recoil from the market so that a limit-trigger is averted. As this leads to depression of liquidity, the model postulates that if some level of randomness were to be introduced into the circuit breaker design, it would attract more liquidity as informed traders would not retire from the order book so easily.

\subsection{Empirical work}

The early empirical demonstration of magnet effect was circuitous. This phenomenon was established by Slezak (1994) in a multi-period market cessation model, where a trading pause rebounds' resolution of information uncertainty and enforces needless risk on both well-informed and retail investors. Among later studies, Ackert et al. (2001) use an experimental 
market model to show that when market agents fear an imminent halt of trading activities, their decision-making time shortens. In other words, they take quick, panicked decisions. This finding was the first behavioral-finance-flavored work in favor of magnet effect hypothesis. In future studies, magnet effect was found in KRX stocks in Korea by Cho et al. (2003). Similar findings were reported by Nath (2005) and Chan et al. (2005). Using a logit approach, Hsieh et al. (2009) confirmed magnet effect's existence in Taiwan, while Du et al. (2009) do the same with an added decomposition of magnet effect from intraday momentum effect. For the Spanish market where a comparatively complex suspension period applies coupled with call auctions, Abad and Pascual (2007) report evidence against the magnet effect using intraday order data. Among emerging markets, magnet effect hypothesis was rejected for Tunisia by Dabbou (2013) and Wan et al. (2015) for Chinese markets. Meanwhile, for Malaysia, an intraday investigation by Sifat and Mohamad (2018a, b) shows the existence of both magnet and its opposite repellent effect with both effects reported as mild. Finally, a recent work by Hautsch and Horvath (2018) demonstrates that the mere existence of limiting mechanisms cause market agents behave differently in the anticipation of an interruption.

\subsection{Shortcomings of the existing literature}

A major limitation of literature on the magnet effect hypothesis is lack of theoretical framework to empirically test the existence of this effect in markets. This is compounded by the paucity of data. The high cost nature of high-frequency and granular historical data impedes employing back-testing to test whether price limits invited a magnet effect when they were first instituted. As a result, even findings of later studies are not comparable for the whole lifetime of a circuit breaker regime. In the absence of robust theoretical grounding, due to a stagnation of theoretical work since Subrahmanyam's (1997) last theoretical paper, the best way of testing the magnet effect hypothesis in academia remains employing experimental testing in various markets and inductively amassing empirical evidence to paint a broad picture.

\section{Objectives}

Having outlined the limitations of the existing theoretical and empirical works on the subject matter till date, the objectives of this paper are to examine whether the magnet effect hypothesis exists in the Malaysian market, the intensity (amplitude) of such an effect, and possible asymmetry - that is whether the effect shows distinguishably different patterns for upper and lower limit scenarios.

\section{Rationale of the study}

Historically, Kuala Lumpur Stock Exchange (KLSE - later renamed as Bursa Malaysia) enacted circuit breaker rules first on May 4, 1989. The stock-specific limits at the time were stipulated at 15 percent per trading session for old listings and 500 percent for new listings. This limit was later doubled to 30 percent on December 15, 1989. From Quarter 1 of 2002, KLSE moved to a three-tiered market-wide circuit breaker is a three-tiered mechanism. Simultaneously, KLSE began migrated to a fully automated trading platform and set a 400 percent upper limit and 30 percent down limit for newly listed (IPO) securities priced over RM1. For below RM1 IPO listings, upper limit was set at 400 percent or 30 sen (cents), whichever is achieved first, and lower limit is 30 sen (cents). In November 2013, Bursa Malaysia further fine-tuned its price limits. While the old limit was simply called price limit, it became known as "static price limit," as another intraday limit was rolled out: dynamic price limit. The dynamic price limit is set: for stocks priced RM1 and above at 8 percent, and for stocks priced below RM1 at 8 sen (cents). Bursa Malaysia justifies this practice through claims of internal study of index movements over a period of time including instances of sudden and sustained deceleration of index as well as a comparative study of international 
JCMS

2,2

124

best practices (Asmar and Ahmad, 2012). The claims of the exchange and regulators that the employed price limits aid in tempering volatility in the market are beyond the scope of this paper. However, that claim leaves out the matter of magnet effect hypothesis. This matter is more theoretical due to its ex ante nature. As such, if it is triggered by design is of significant import not just to Malaysian regulators but also academics and regulators worldwide. The last empirical attempt in the Malaysian market by Chan et al. (2005) was based on a sample period 1995-1996. Not only was that sample period very short, its findings are nearly obsolete now in practical terms. As such, a fresh study employing a longrange data set promises a deeper insight into answering the magnet effect puzzle.

\section{Data description and study methodology}

\subsection{Sample selection}

The proprietary data set purchased for this paper includes "open, high, low, close, volume" data from 1977 to 2017. Though circuit breakers had been in place since 1989, their occurrences were sporadic up until 1993. To ensure a meaningful investigation, thinly traded stocks were truncated at first. Then we sort the remaining stocks according to a combination of trading volume and market capitalization and select 150 active stocks with at least two limit or pseudo-limit hits from January 1994 to February 16, 2017. These 150 stocks from both main and second (ACE) board account for 29 percent of BM/KLSE market capitalization for the period of study and constitute 34 percent of total turnover. We divide the samples into three subsample groups based on different price limit regimes. The first regime, from 1994 to 2002 represents a 30 percent price limit per trading session. Thus, theoretically, a morning upper limit hit of 30 percent followed by an afternoon limit hit of 30 percent can theoretically accommodate a 69 percent close-to-close jump, or a 51 percent fall in case of consecutive lower limits in the same trading day in Regime 1. The next regime, from 2002 to 2011, carries the "per session" limit rule, except that in this period market-wide circuit breakers were tightened, the exchange was demutualized and listed, market-makers were introduced, and regulated short selling (RSS) was reintroduced. But most significantly, in early 2002 theoretical opening prices were implemented, signaling a shift from previous daily opening price determination based on first transaction. Consequently, the period between 2002 and 2011 merits a distinct regime due to fundamental changes to market constitution and trading mechanisms. The third regime begins from November 2011, whereby "per session" limit rule of 30 percent was scrapped and daily static limit of 30 percent was instituted. The selected samples of 150 stocks with 2,726 limit and pseudo-limit hits are appended as an image (Figure 1) at the end of the paper due to formatting reasons.

Since Bursa Malaysia's price limit is very wide, limit hits have been infrequent compared to more active limit markets such as Taiwan, China, and Korea. Our sampling yielded 2,729 limit hits and pseudo-limit hits for upper limit. Out of these, 1,468 occurred in Regime 1,116 in Regime 2, and 147 in Regime 3. For the lower limit, we find a total of 1,873 limit and pseudo-limit hits: 1,005 in Regime 1,772 in Regime 2, and 96 in Regime 3. Full limit hits were 133 for upper band and 98 for lower band, respectively. The higher ratio of upper limits is consistent with sampling of Chan et al. (2005), who observed 110 limits in the period between 1995 and 1996. They found only five lower limit hits in that period since 1995-1996 marked an aggressive bullish period in Asian Tiger stock markets.

\subsection{Study design}

The magnet effect theory entails a high likelihood of price surpassing upper or lower limits as price approaches those limits (Subrahmanyam, 1994). The probability of price reaching the limit is tested via overnight price returns $\left(R_{\text {overnight }}\right)$, which establishes the closeness of price to upper or lower limit the next morning. Previous researchers observe that the 
An investigation

of magnet effect

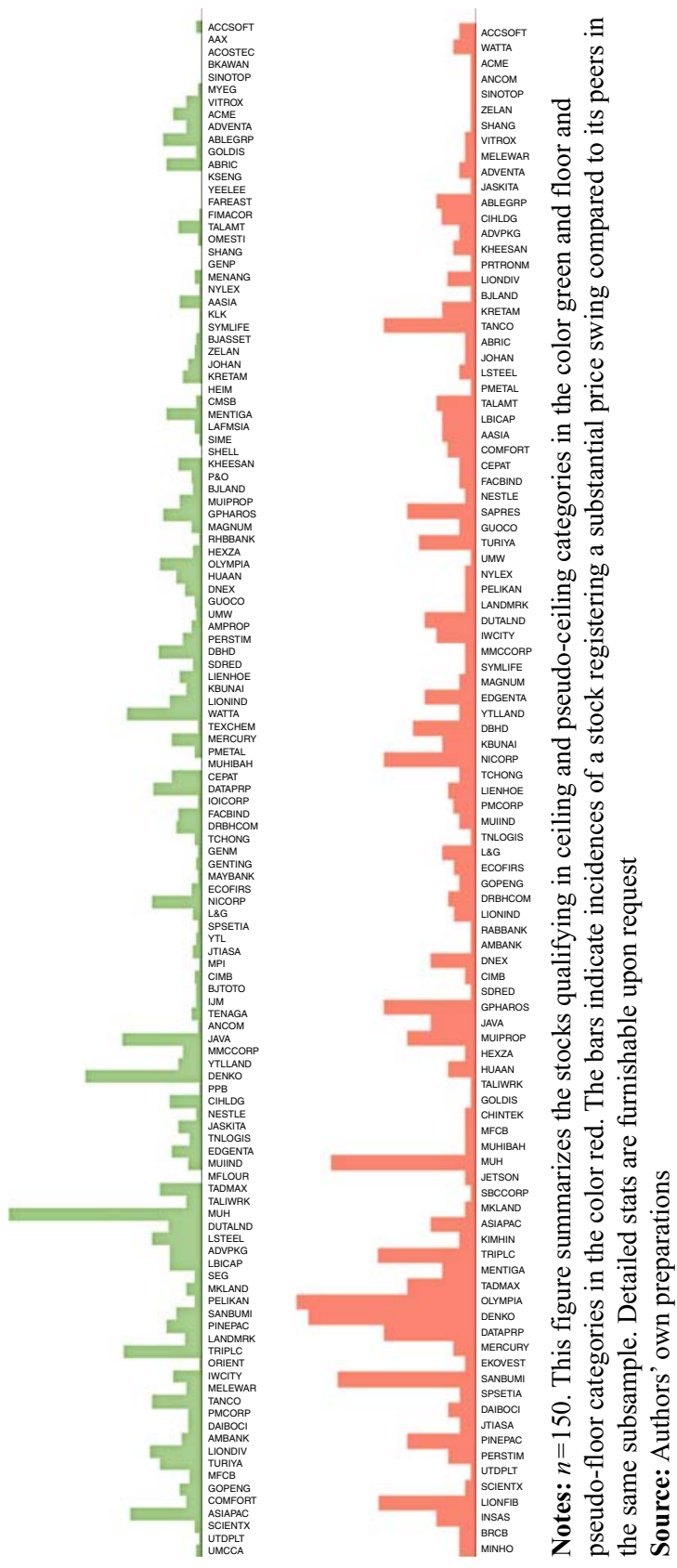

Figure 1. Upward and downward move stocks under study 
JCMS

2,2

126

magnitude of overnight return is correlated with likelihood of price hitting the limit the next day (George and Hwang, 1995; Kim and Rhee, 1997). We investigate how that probability behaves when limits are in place. A high probability result will be indicative of magnet effect and the opposite a repellant or calming effect. To achieve this, two logistic regression models are invoked. The first deals with probability of price rising by the limit amount in a given close-to-close (CTC) scenario. The other deals with probability of price falling by the limit amount in each CTC scenario. In addition to overnight returns, the independent variables in the proposed benchmark model incorporate two trading days' worth of overnight lag (CTC) and intraday (OTC) returns, volatility, and dummy variables to see if a limit is hit on $t-1$ and $t-2$. The benchmark equation thus stands as follows:

$$
\begin{aligned}
D_{t}= & \alpha_{0}+\theta_{1 R_{\text {overnight }, t}}+\sum\left(\mu_{1} R_{\text {intraday, },-1}+\theta_{2} R_{\text {overnight }, t-1}\right) \\
& +\beta_{1} R_{t-1}+\gamma_{1} V O L_{t}+\pi_{1} D_{t-1}+\pi_{2} D_{t-2}+\pi_{n}\left(M_{\text {M ANET }}\right)+\varepsilon_{t} .
\end{aligned}
$$

here $D_{t}$, dummy variable, which captures the asset's inter-day return (CTC) reaches based on scenarios where a limit (30 percent in a session for Regimes 1 and 2, and per day in Regime 3 ) or pseudo-limit (21 percent per session for Regimes 1 and 2, and per day for Regime 3 ) has been breached on day $t$. $R_{\text {overnight }}=$ overnight return (close to open, CTO) on day $t$. This is calculated as a natural log of (open/close). It is normalized by first deducting stock-specific mean and thereby dividing by the stock-specific standard deviation. $R_{\text {intraday }}=$ intraday return (open to close (OTC)) on day $t$. This is calculated as a natural log of (close/open). It is normalized by first deducting asset-specific mean and thereby dividing by the asset-specific standard deviation. $\mathrm{VOL}_{t}=$ volatility, calculated as a mean of squared returns over the previous five trading days.

Our independent variable of prime interest is $R_{\text {overnight }}$. A sizeable increase in $R_{\text {overnight }}$ 's coefficient in limit and pseudo-limit hit windows are construed as indicative of magnet effect. The lagging returns enable testing for autocorrelation, which are usually higher in frontier markets compared to developed markets (Farag, 2013). The rationale for incorporating volatility in the equation stems from the existence of a strong autocorrelation of volatility in most financial markets in the world (Avdis, 2016). Higher volatility in the previous days raises the chance that prices will hit the limit on the day of question. The lagging dummies are expected to be more significant in the limit windows than pseudo-limit windows, since the suppression of volatility upon limit hits on the day $t$ may splatter to future days/sessions. To establish an appropriate number of additional return lags, we re-estimate the model several times and dismiss insignificant terms. After re-estimations, we settled for two additional return lags.

\section{Results and analysis}

Our findings are suggestive of magnet effect in KLSE/BM throughout the three different regimes. A pivotal indicator in identifying the existence of magnet effect, according to our benchmark model, is the coefficient of the overnight returns variable. As shown in Tables II-IV, an increase in the coefficient is observed between the hit and pseudo-hit groups for all three regimes. The rise is most pronounced in Regime 2, and least in Regime 3. This applies to both limit-up and limit-down scenarios. For the upper limit, the coefficient rises from 8.219 to 21.542, from 9.963 to 26.249 , and from 5.848 to 15.69 for the three regimes, respectively. For the lower limit, the same effect decreases from -8.319 to -5.667 in Regime 1 and -10.897 to -6.335 for Regime 2, but intensified from -5.157 to -6.392 for Regime 3 . The aggression in upper limit coefficient values compared to lower limit could be attributed to constrictions on short selling in KLSE-BM over the sampling period. Short selling was first introduced in 1996 but soon scrapped in 1997 around the Asian financial crisis - corresponding to Regime 1 of our sampling period. It was reintroduced in 2007 (Regime 2 of sampling period) as RSS and is available via securities borrowing and lending mechanism under strict supervision of the exchange's 
negotiated transactions model. Even then, the privilege of selling short is afforded to institutional investors only. The pool of securities available to short under RSS has been widening gradually since 2013, and the magnitude of overnight returns' coefficients align with the regulatory demands. This is also explainable by the inability of the bears and contrarian contingent of the market to trade (and profit) in tandem with the bearish sentiment.

Tables I-VI exhibit acceptable regression results with the maximum log likelihood (MLL) ratio at acceptable ranges with $95 \%$ confidence level. The explanatory powers, too, are adequate - ranging from Cox-Snell $R^{2}$ values of 31-49 percent. Unsurprisingly, the coefficients on volatility are consistently positive, and significant. Also, coefficients on additional lagging returns suggest substantial return autocorrelation. To corroborate these findings, we run the MLL of triggering a limit-up or limit-down scenario, for a specific overnight return for eight individual stocks, on an experimental basis. We fail to achieve convergence for only two stocks. For the remaining six, the Cox-Snell $R^{2}$ values ranged from 32 to 59 percent, with a mean of 44 percent. Respective limit-up and limit-down
An investigation of magnet effect

\begin{tabular}{|c|c|c|c|c|c|}
\hline & Hit group & Hit group (marginal effect) & Pseudo-hit group & Pseudo hit (marginal effect) & \\
\hline$R_{\text {overnight }, t}$ & 8.219 & 0.313 & 21.542 & 0.597 & \\
\hline$D R_{\text {overnight, } t}$ & 13.323 & 0.102 & 10.548 & 0.498 & \\
\hline$R_{\text {intraday, } t-1}$ & 9.767 & 0.617 & 5.433 & 0.107 & \\
\hline$R_{\text {overnight }, t-1}$ & 3.201 & 0.103 & 2.109 & 0.093 & \\
\hline$R_{\text {intraday, } t-2}$ & 1.046 & 0.111 & 1.165 & 0.119 & \\
\hline$R_{\text {overnight } t-2}$ & 0.446 & 0.068 & 2.898 & 0.483 & \\
\hline$V O L_{t}$ & 0.452 & 0.188 & 1.332 & 0.579 & \\
\hline$D_{t-1}$ & 3.457 & 0.134 & 1.229 & 0.065 & \\
\hline$D D_{t-1}$ & 1.104 & 0.162 & -0.127 & 0.099 & \\
\hline$D_{t-2}$ & 2.109 & 0.286 & 1.998 & 0.302 & \\
\hline$D D_{t-2}$ & 2.084 & 0.107 & 1.836 & 0.102 & \\
\hline Constant & -6.588 & 0.370 & -3.623 & 0.105 & Table I. \\
\hline MLL ratio & 587.337 & & 878.113 & & Logit regression \\
\hline Cox-Snell $R^{2}$ & 0.399 & & 0.414 & & report on likelihood of \\
\hline$H-L$ Stat & 24.791 & & 31.552 & & ceiling hit (Regime 1: \\
\hline$p$-value & 0.043 & & 0.057 & & 1994-2002) \\
\hline
\end{tabular}

\begin{tabular}{|c|c|c|c|c|c|}
\hline & Hit group & Hit group (marginal effect) & Pseudo hit group & Pseudo hit (marginal effect) & \\
\hline$R_{\text {overnight }, t}$ & 9.963 & 0.296 & 26.249 & 0.143 & \\
\hline$D R_{\text {overnight }, t}$ & 16.286 & 0.153 & 10.220 & 0.073 & \\
\hline$R_{\text {intraday, } t-1}$ & 13.479 & 0.081 & 6.302 & 0.045 & \\
\hline$R_{\text {overnight }, t-1}$ & 4.418 & 0.099 & 2.447 & 0.230 & \\
\hline$R_{\text {intraday, } t-2}$ & 1.444 & 0.211 & 1.351 & 0.139 & \\
\hline$R_{\text {overnight } t-2}$ & 0.615 & 0.098 & 3.362 & 0.147 & \\
\hline$V O L_{t}$ & 0.624 & 0.259 & 1.546 & 0.068 & \\
\hline$D_{t-1}$ & 4.149 & 0.165 & 1.425 & 0.003 & \\
\hline$D D_{t-1}$ & 1.325 & 0.434 & -0.147 & 0.115 & \\
\hline$D_{t-2}$ & 2.530 & 0.350 & 2.318 & 0.510 & \\
\hline$D D_{t-2}$ & 2.501 & 0.408 & 2.130 & 0.278 & \\
\hline Constant & -7.906 & 0.143 & -4.203 & 0.122 & Table II. \\
\hline MLL ratio & 681.201 & & 607.694 & & Logit regression \\
\hline Cox-Snell $R^{2}$ & 0.444 & & 0.368 & & report on likelihood of \\
\hline$H-L$ stat & 37.442 & & 28.587 & & ceiling hit in Regime 2 \\
\hline$p$-value & 0.033 & & 0.106 & & $(2002-2013)$ \\
\hline
\end{tabular}


JCMS

2,2

Hit group Hit group (marginal effect) Pseudo hit group Pseudo hit group (marginal effect)

5.848

9.842

7.912

2.593

0.806

0.343

Table III.

Logit regression report on likelihood of ceiling hit during

Regime 3 (2013-2017)
0.748

2.612

0.850

1.624

1.605

$R_{\text {overnight, } t-2}$

$V O L_{t}$

$D D_{t-1}$

$D_{t-2}$

$D D_{t-2}$

Constant

MLL eatio

$-4.013$

Cox-Snell $R^{2} \quad 563.121$

$H-L$ stat $\quad 27.141$

$p$-value

0.210
0.109
0.057
0.070
0.150
0.070
0.184
0.117
0.308
0.248
0.290
0.102

15.690

$9.068-0.126$

$5.735 \quad 0.039$

$2.277 \quad 0.202$

$\begin{array}{ll}1.229 & 0.122\end{array}$

$3.059 \quad 0.130$

$1.449-0.060$

$1.336 \quad 0.003$

$\begin{array}{ll}-0.138 & 0.101\end{array}$

$2.173 \quad 0.449$

$1.997 \quad 0.245$

$\begin{array}{ll}-3.939 & 0.107\end{array}$

589.365

0.313

28.672

0.156

Hit group Hit group (marginal effect) Pseudo hit group Pseudo hit group (marginal effect)

Table IV.

Logit regression report on likelihood of floor hit during Regime 1 (1994-2002)

\begin{tabular}{lcccc}
\hline & Hit group & Hit group (marginal effect) & Pseudo hit group & Pseudo hit group (marginal effect) \\
\hline$R_{\text {overnight. } T}$ & -8.319 & 0.260 & -5.657 & 0.244 \\
$D R_{\text {overnight. } T}$ & -9.673 & 0.085 & -6.577 & 0.080 \\
$R_{\text {intraday, } t-1}$ & -7.091 & 0.512 & -4.822 & 0.282 \\
$R_{\text {overnight }, t-1}$ & -2.324 & 0.085 & -1.580 & 0.088 \\
$R_{\text {intraday, } t-2}$ & -0.760 & 0.092 & -0.517 & 0.086 \\
$R_{\text {overnight, } t-2}$ & -0.324 & 0.057 & -0.220 & 0.053 \\
$V O L_{t}$ & -0.328 & 0.156 & -0.223 & 0.156 \\
$D_{t-1}$ & -2.510 & 0.111 & -1.707 & 0.105 \\
$D D_{t-1}$ & -0.802 & 0.134 & -0.545 & 0.126 \\
$D_{t-2}$ & -1.531 & 0.237 & -1.041 & 0.223 \\
$D D_{t-2}$ & -1.513 & 0.089 & -1.029 & 0.239 \\
Constant & -3.339 & 0.307 & -2.902 & \\
MLL ratio & 903.221 & & 808.671 & \\
Cox-Snell $R^{2}$ & 0.471 & & 0.424 & \\
$H-L$ stat & 38.811 & & 31.207 & \\
$p$-value & 0.044 & & 0.089 & \\
\end{tabular}

scenarios' concurrent overnight returns had persistently positive values for limit-up, and negative values for limit-down, barring two exceptions (Table VII).

Having identified streaks of magnet effect in all three regimes (with second being the strongest and third being weakest), we concede a possibility that a change in coefficient signage on concurrent overnight returns may not necessarily capture the effect of price limits but rather represent an unaccounted effect. To examine this contingency, we present nonnested logistic regression reports, whereby all coefficients are permitted to change between periods. As seen in Tables VIII-XIII, the coefficient changes on overnight returns continue their momentum in limit-up and limit-down scenarios. The former rises from 7.562 to 19.82 , 8.968 to 25.234 , and 7.713 to 20.091 for Regimes 1, 2, and 3, respectively. Similarly, limit-down coefficients for the three regimes in non-nested regressions fall from -7.329 to $-15.348,-9.293$ to -18.94 , and -4.121 to -8.529 . As with nested regression reports earlier, coefficient changes are more pronounced in limit-up cases, although asymmetry between the two limits is less extreme in non-nested reports. 
Hit group Hit group (marginal effect) Pseudo hit group Pseudo hit group (marginal effect)

An investigation of magnet effect

\begin{tabular}{|c|c|c|c|c|c|}
\hline$R_{\text {overnight } t}$ & -10.897 & 0.340 & -6.335 & 0.315 & \\
\hline DRernght, $t$ & -12.671 & 0.111 & -7.367 & 0.103 & \\
\hline$R_{\text {intraday, } t-1}$ & -9.289 & 0.671 & -5.401 & 0.363 & \\
\hline$R_{\text {overnight, } t-1}$ & -3.045 & 0.112 & -1.770 & 0.114 & \\
\hline$R_{\text {intraday, } t-2}$ & -0.995 & 0.120 & -0.579 & 0.111 & \\
\hline$R_{\text {overnight } t-2}$ & -0.424 & 0.074 & -0.246 & 0.069 & 129 \\
\hline$V O L_{t}$ & -0.430 & 0.204 & -0.250 & 0.202 & \\
\hline$D_{t-1}$ & -3.288 & 0.146 & -1.912 & 0.135 & \\
\hline$D D_{t-1}$ & -1.050 & 0.176 & -0.611 & 0.163 & \\
\hline$D_{t-2}$ & -2.006 & 0.311 & -1.166 & 0.088 & \\
\hline$D D_{t-2}$ & -1.982 & 0.116 & -1.152 & 0.108 & \\
\hline Constant & -4.374 & 0.402 & -3.250 & 0.211 & Table V. \\
\hline MLL ratio & 703.212 & & 687.103 & & Logit regression \\
\hline Cox-Snell $R^{2}$ & 0.412 & & 0.403 & & report on likelihood of \\
\hline$H-L$ stat & 28.116 & & 29.704 & & lower floor hit in \\
\hline$p$-value & 0.041 & & 0.069 & & Regime 2 (2002-2013) \\
\hline
\end{tabular}

Hit group Hit group (marginal effect) Pseudo hit group Pseudo hit group (marginal effect)

\begin{tabular}{lrlrr}
\hline$R_{\text {overnight }, t}$ & -5.157 & 0.241 & -6.392 & 0.152 \\
$D_{\text {overnight }, t}$ & -5.997 & 0.079 & -8.433 & 0.021 \\
$R_{\text {intraday, } t-1}$ & -4.396 & 0.477 & -5.449 & 0.182 \\
$R_{\text {overnight }, t-1}$ & -1.441 & 0.079 & -1.786 & 0.027 \\
$R_{\text {intraday, } t-2}$ & -0.471 & 0.085 & -0.584 & 0.026 \\
$R_{\text {overnight } t-2}$ & -0.201 & 0.053 & -0.249 & -0.001 \\
VOL & -0.203 & 0.145 & -0.252 & 0.082 \\
$D_{t-1}$ & -1.556 & 0.104 & -1.929 & 0.040 \\
$D D_{t-1}$ & -0.497 & 0.125 & -0.616 & 0.058 \\
$D_{t-2}$ & -0.949 & 0.221 & -1.176 & 0.135 \\
$D D_{t-2}$ & -0.938 & 0.083 & -1.163 & 0.024 \\
Constant & -2.070 & 0.285 & -3.279 & 0.148 \\
MLL ratio & 553.661 & & 674.208 & \\
Cox-Snell $R^{2}$ & 0.481 & & 0.392 & \\
$H-L$ stat & 26.558 & & 33.128 & \\
$p$-value & 0.023 & & 0.044 & \\
Notes: & & & &
\end{tabular}

Notes: Tables I-VI show results from the logistic benchmark model estimation regarding the likelihood that prices for the limit and pseudo-limit subgroups move upwards or downwards by the amount of the respective price bands (30 percent for limit, 21 percent for pseudo-limit). All values (except italicized) are significant at $95 \%$ confidence. The variables derive from Equation (1)

Table VI.

Logit regression report on likelihood of floor hit in regime 3 (2013-2017)

To overcome the deficits of CTC volatility estimations, we choose to engage Yang-Zhang OHLC volatility estimator, which is a weighted average of the Rogers-Satchell model, overnight, and intraday volatility model (Yang and Zhang, 2000):

$$
\sigma_{g k y z}=\sqrt{\frac{F}{n}} \sqrt{\sum_{i=1}^{n}\left(\ln \left(\frac{o_{i}}{c_{i-1}}\right)\right)^{2}+\frac{1}{2}\left(\ln \left(\frac{h_{i}}{l_{i}}\right)\right)^{2}-(2 \ln (2)-1)\left(\ln \left(\frac{c_{i}}{o_{i}}\right)\right)^{2}} .
$$

The re-estimated results are congruent with those reported in Tables VIII-XIII. Finally, we modify our benchmark model to account for potential speculative dynamics (Arak and Cook, 1997). 
JCMS

2,2

130

Table VII

Nested-logit results for ceiling hits in regime 1

(1994-2002)

Hit group Hit group (marginal effect) Pseudo hit group Pseudo hit group (marginal effect)

\begin{tabular}{lrrrl}
\hline$R_{\text {overnight, } t}$ & 7.562 & 0.308 & 8.215 & 0.615 \\
$D R_{\text {overnight }, t}$ & 12.258 & 0.101 & 10.864 & 0.513 \\
$R_{\text {intraday, } t-1}$ & 8.986 & 0.608 & 5.596 & 0.111 \\
$R_{\text {overnight, } t-1}$ & 2.945 & 0.101 & 2.173 & 0.096 \\
$R_{\text {inntraday, } t-2}$ & 0.963 & 0.109 & 1.199 & 0.123 \\
$R_{\text {overnight }, t-2}$ & 0.410 & 0.067 & 2.985 & 0.498 \\
$V O L_{t}$ & 0.416 & 0.185 & 1.372 & 0.596 \\
$D_{t-1}$ & 3.181 & 0.132 & 1.266 & 0.067 \\
$D D_{t-1}$ & 1.016 & 0.159 & -0.131 & 0.102 \\
$D_{t-2}$ & 1.940 & 0.282 & 2.058 & 0.311 \\
$D D_{t-2}$ & 1.917 & 0.105 & 1.891 & 0.105 \\
Constant & -6.061 & 0.364 & -3.732 & \\
MLL ratio & 701.280 & & 744.743 & \\
Cox-Snell $R^{2}$ & 0.462 & & 0.514 & \\
$H-L$ stat & 27.345 & & 30.791 & \\
$p$-value & 0.024 & & 0.022 & \\
& & & &
\end{tabular}

Hit group Hit group (marginal effect) Pseudo hit group Pseudo hit group (marginal effect)

Table VIII.

Nested logit results on likelihood of ceiling hit in Regime 2 (2002-2013)

\begin{tabular}{lrrrc}
\hline & Hit group & Hit group (marginal effect) & Pseudo hit group & Pseudo hit group (marginal effect) \\
\hline$R_{\text {overnight }, t}$ & 8.968 & 0.424 & 9.678 & 0.827 \\
$D R_{\text {overnight }, t}$ & 16.266 & 0.111 & 15.373 & 0.737 \\
$R_{\text {intraday, } t-1}$ & 10.352 & 0.697 & 6.737 & 0.159 \\
$R_{\text {overnight, } t-1}$ & 3.808 & 0.147 & 2.655 & 0.122 \\
$R_{\text {intraday }, t-2}$ & 1.191 & 0.152 & 1.373 & 0.165 \\
$R_{\text {overnight }, t-2}$ & 0.586 & 0.091 & 3.779 & 0.643 \\
$V O L_{t}$ & 0.461 & 0.205 & 1.967 & 0.769 \\
$D_{t-1}$ & 4.144 & 0.189 & 1.549 & 0.137 \\
$D D_{t-1}$ & 1.434 & 0.207 & -0.171 & 0.393 \\
$D_{t-2}$ & 2.435 & 0.402 & 2.984 & 0.150 \\
$D D_{t-2}$ & 2.489 & 0.152 & 2.130 & 0.132 \\
Constant & -7.655 & 0.474 & -5.019 & \\
MLL ratio & 659.098 & & 657.608 & \\
Cox-Snell $R^{2}$ & 0.449 & & 0.460 & \\
$H-L$ stat & 26.388 & & 26.726 & \\
$p$-value & 0.020 & & 0.019 & \\
& & &
\end{tabular}

Traders with such an interpretation could either escalate or undermine the magnet effect. Alternatively, intraday traders or scalpers may choose to remain on the sidelines if they expect that their anticipated intraday returns from riding the trend contrails are skewed toward losses; thus, any strong sustainable trend would be limited, and reversal would be natural. Therefore, following Cho et al. (2003), we invoke two magnet dummies to capture speculative ceilings and floors (Equation (2)):

$$
\begin{aligned}
\text { MAGNET } T_{\text {ceiling }, t}= & \text { Unity, if } R_{\text {overnight }, t}>0, R_{\text {day }, t-1}>0 \ldots R_{\text {overnight }, t} \\
& <R_{\text {day }, t-1} \text {; otherwise } 0, \\
\text { MAGNET } T_{\text {floor }, t}= & \text { Unity, if } R_{\text {overnight }, t}<0, R_{\text {day }, t-1}<0 \ldots R_{\text {overnight }, t} \\
& <R_{\text {day }, t-1} \text {; otherwise } 0 .
\end{aligned}
$$


it group Hit group (marginal effect) Pseudo hit group Pseudo hit group (marginal effect)

An investigation of magnet effect

\begin{tabular}{|c|c|c|c|c|c|}
\hline & & & & & \\
\hline$R_{\text {overnight }, t}$ & 7.713 & 0.238 & 4.889 & 0.096 & \\
\hline$D R_{\text {overnight }, t}$ & 12.378 & 0.119 & 8.708 & 0.062 & \\
\hline$R_{\text {intraday, } t-1}$ & 9.395 & 0.054 & 6.208 & 0.042 & \\
\hline$R_{\text {overnight, } t-1}$ & 4.303 & 0.087 & 2.183 & 0.212 & \\
\hline$R_{\text {intraday, } t-2}$ & 1.184 & 0.175 & 1.054 & 0.116 & \\
\hline$R_{\text {overnight }, t-2}$ & 0.553 & 0.082 & 2.602 & 0.115 & 131 \\
\hline$V O L_{t}$ & 0.504 & 0.218 & 1.079 & 0.052 & \\
\hline$D_{t-1}$ & 3.779 & 0.123 & 1.013 & 0.002 & \\
\hline$D D_{t-1}$ & 0.993 & 0.421 & -0.114 & 0.114 & \\
\hline$D_{t-2}$ & 1.903 & 0.276 & 1.569 & 0.447 & \\
\hline$D D_{t-2}$ & 1.793 & 0.398 & 1.934 & 0.210 & \\
\hline Constant & -6.657 & 0.108 & -3.997 & 0.121 & Table IX. \\
\hline MLL ratio & 750.053 & & 781.690 & & Nested logit results on \\
\hline Cox-Snell $R^{2}$ & 0.507 & & 0.613 & & likelihood of ceiling \\
\hline$H-L$ stat & 31.375 & & 36.897 & & hit in Regime 3 \\
\hline$p$-value & 0.023 & & 0.025 & & (2013-2017) \\
\hline
\end{tabular}

Hit group Hit group (marginal effect) Pseudo hit group Pseudo hit group (marginal effect)

\begin{tabular}{|c|c|c|c|c|c|}
\hline$R_{\text {overnight } T}$ & -7.329 & 0.229 & -6.347 & 0.207 & \\
\hline$D R_{\text {overnight. } T}$ & -8.019 & 0.069 & -6.672 & 0.059 & \\
\hline$R_{\text {intraday }, t-1}$ & -6.354 & 0.437 & -5.343 & 0.389 & \\
\hline$R_{\text {overnight } t-1}$ & -1.885 & 0.069 & -1.640 & 0.062 & \\
\hline$R_{\text {intraday, } t-2}$ & -0.641 & 0.074 & -0.583 & 0.066 & \\
\hline$R_{\text {overnight }, t-2}$ & -0.292 & 0.046 & -0.244 & 0.039 & \\
\hline$V O L_{t}$ & -0.287 & 0.128 & -0.260 & 0.104 & \\
\hline$D_{t-1}$ & -2.214 & 0.091 & -1.928 & 0.074 & \\
\hline$D D_{t-1}$ & -0.680 & 0.120 & -0.547 & 0.106 & \\
\hline$D_{t-2}$ & -1.315 & 0.190 & -1.185 & 0.164 & \\
\hline$D D_{t-2}$ & -1.260 & 0.079 & -1.035 & 0.067 & \\
\hline Constant & -2.731 & 0.254 & -2.262 & 0.229 & Table X. \\
\hline MLL ratio & 776.770 & & 636.951 & & Nested logit results on \\
\hline Cox-Snell $R^{2}$ & 0.414 & & 0.334 & & likelihood of floor hit \\
\hline$H-L$ stat & 35.318 & & 28.996 & & in Regime 1 \\
\hline$p$-value & 0.038 & & 0.093 & & (1994-2002) \\
\hline
\end{tabular}

The split-sample regressions reported in Tables I-VI are re-estimated adding the two dummy variables. The results (Table XIII) indicate that acceleration toward floor is irrelevant to the likelihood of large downward price thrust leading to limit-down trigger, suggesting evidence of magnet effect. The effect of upward (downward) acceleration on the conditional likelihood that prices rise (fall) by 30 percent or more increases extensively for limit-hit groups. Accordingly, we note that when returns accelerate overnight compared to the previous day, traders may interpret it as a forerunner of limit-trigger and thus hasten their trades in a way that a limit is reached. These results consistently indicate that the imposition of price limits on Bursa Malaysia evince a magnet effect. This is evident for both upper and lower limits but is more pronounced in upper limits.

In light of all controversies surrounding limits' effectiveness, some opine that it is extremely hard to design market venues which can directly aid in stabilizing financial markets since large-scale economic experiments are impossible to carry out in a real exchange. As such, artificial computer experiments can bridge this gap in analysis of 
JCMS

2,2

132

Table XI.

Nested logit report on likelihood of floor hit in Regime 2

(2002-2013)
Hit group Hit group (marginal effect) Pseudo hit group Pseudo hit group (marginal effect)

\begin{tabular}{lrrrr}
\hline$R_{\text {overnight. } T}$ & -9.293 & 0.289 & -7.959 & 0.258 \\
$D_{\text {overnight. } T}$ & -9.647 & 0.086 & -8.593 & 0.074 \\
$R_{\text {intraday, } t-1}$ & -8.177 & 0.557 & -6.909 & 0.477 \\
$R_{\text {overnight, } t-1}$ & -2.356 & 0.083 & -2.028 & 0.075 \\
$R_{\text {intraday, } t-2}$ & -0.833 & 0.089 & -0.751 & 0.079 \\
$R_{\text {overnight, } t-2}$ & -0.361 & 0.057 & -0.304 & 0.051 \\
$V_{O L} L_{t}$ & -0.351 & 0.158 & -0.330 & 0.129 \\
$D_{t-1}$ & -2.878 & 0.115 & -2.460 & 0.096 \\
$D D_{t-1}$ & -0.820 & 0.145 & -0.685 & 0.138 \\
$D_{t-2}$ & -1.653 & 0.244 & -1.438 & 0.202 \\
$D D_{t-2}$ & -1.627 & 0.100 & -1.311 & 0.084 \\
Constant & -3.319 & 0.317 & -2.859 & 0.289 \\
MLL ratio & 971.739 & & 821.030 & \\
Cox-Snell $R^{2}$ & 0.504 & & 0.404 & \\
$H-L$ stat & 44.748 & & 35.607 & \\
$p$-value & 0.048 & & 0.041 &
\end{tabular}

Table XII.

Nested logit report on likelihood of floor hit in Regime 3 (2003-2017)

Hit group Hit group (marginal effect) Pseudo hit group Pseudo hit group (marginal effect)

\begin{tabular}{lrrrr}
\hline$R_{\text {overnight, } t}$ & -4.121 & 0.212 & -3.581 & 0.250 \\
$D_{\text {overnight }, t}$ & -4.408 & 0.064 & -2.958 & 0.081 \\
$R_{\text {intraday, } t-1}$ & -3.856 & 0.326 & -3.351 & 0.412 \\
$R_{\text {overnight }, t-1}$ & -1.102 & 0.058 & -0.843 & 0.072 \\
$R_{\text {intraday, } t-2}$ & -0.409 & 0.077 & -0.330 & 0.102 \\
$R_{\text {overnight, } t-2}$ & -0.144 & 0.043 & -0.121 & 0.055 \\
$V O L_{t}$ & -0.156 & 0.119 & -0.133 & 0.153 \\
$D_{t-1}$ & -1.307 & 0.071 & -0.984 & 0.092 \\
$D D_{t-1}$ & -0.380 & 0.085 & -0.264 & 0.107 \\
$D_{t-2}$ & -0.729 & 0.178 & -0.528 & 0.225 \\
$D D_{t-2}$ & -0.750 & 0.057 & -0.595 & 0.065 \\
Constant & -1.681 & 0.254 & -1.461 & 0.287 \\
MLL ratio & 575.595 & & 635.294 & \\
Cox-Snell $R^{2}$ & 0.387 & & 0.326 & \\
$H-L$ stat & 22.627 & & 16.948 & \\
$p$-value & 0.039 & & 0.046 &
\end{tabular}

Notes: Tables VII-XII present results from the nested logistic benchmark model estimation regarding the likelihood that prices for the limit and pseudo-limit subgroups move upwards or downwards by the amount of the respective price bands (30 percent for limit, 21 percent for pseudo-limit). All values (except italicized) are significant at $95 \%$ confidence. The variables derive from Equation (1) and are re-estimated

market traits that are unattended to by conventional finance and economics. Moreover, individual decision making (micro) and choices made at the top level (macro) could shed more light into explanation of market phenomenon like magnet effect.

\section{Managerial implications, limitations, and future research}

The findings of this study have implications for portfolio managers, retail and institutional investors, regulators, and policymakers. For investors and managers, the evidence of magnet effect suggests that profitable trading opportunities could be pursued by ganging up on an intraday trade once established following a substantial price swing at a rate near the limit-trigger. Moreover, since short selling is highly restricted, the asymmetric nature of 


\begin{tabular}{|c|c|c|c|c|c|}
\hline & Limit up & Limit up (marginal effect) & Limit down & Limit down (marginal effect) & f maonet effe \\
\hline \multicolumn{5}{|c|}{ Panel A: Regime 1 (1994-2002) } & \\
\hline$M A G N E T_{\text {ceilin }, t}$ & 0.683 & 0.187 & 0.015 & 0.112 & \\
\hline$M A G N E T_{\text {floor }, t}$ & 0.071 & 0.205 & 0.361 & 0.026 & \\
\hline Constant & -2.052 & 0.130 & -1.427 & 0.128 & \\
\hline MLL ratio & 456.060 & & 406.885 & & \\
\hline Cox-Snell $R^{2}$ & 0.596 & & 0.442 & & 133 \\
\hline \multicolumn{5}{|c|}{ Panel B: Regime 2 (2002-2013) } & \\
\hline MAGNET ceiling, $t$ & 0.702 & 0.256 & 0.019 & 0.156 & \\
\hline$M A G N E T_{\text {floor }, t}$ & 0.097 & 0.264 & 0.513 & 0.039 & \\
\hline Constant & -2.878 & 0.193 & -2.101 & 0.188 & \\
\hline MLL ratio & 512.317 & & 448.662 & & \\
\hline Cox-Snell $R^{2}$ & 0.551 & & 0.409 & & \\
\hline \multicolumn{5}{|c|}{ Panel C: Regime 3 (2003-2017) } & \\
\hline$M A G N E T_{\text {ceiling }, t}$ & 0.527 & 0.188 & 0.014 & 0.120 & \\
\hline$M A G N E T_{\text {floor }, t}$ & 0.066 & 0.177 & 0.390 & 0.029 & \\
\hline Constant & -2.187 & 0.138 & -1.462 & 0.136 & \\
\hline MLL ratio & 499.095 & & 415.090 & & Table XIII. \\
\hline Cox-Snell $R^{2}$ & 0.384 & & 0.478 & & $\begin{array}{l}\text { Table XIII. } \\
\text { Logistic regression }\end{array}$ \\
\hline \multicolumn{5}{|c|}{$\begin{array}{l}\text { Notes: This table presents results from the modified second logistic benchmark model regarding the } \\
\text { acceleration of price on limit and pseudo-limit scenarios. All values (except italicized) are significant at } 95 \% \\
\text { confidence (Equations (2)-(4)) }\end{array}$} & $\begin{array}{r}\text { report on likelihood of } \\
\text { upper and } \\
\text { lower limit hits }\end{array}$ \\
\hline
\end{tabular}

magnet effort suggests a quicker than usual trailing-loss or stop-loss strategy could be beneficial when price pressure is downward. For regulators and policymakers, the evidence of magnet effect finding is unflattering. It suggests that instead of lowering volatility in high-price-change scenarios, the price limits themselves encourage traders to hit the limit price. This is particularly puzzling considering the \pm 30 percent limit employed in Malaysia is already unusually wide. Widening the limit furthermore would make the practice truly aberrant on a worldwide scale.

One limitation of this study is the inability to use intraday data for studying the magnet effect. Since magnet effect is captured by the aggression of the order flows, lack of such data availability makes it very difficult to truly record findings that cannot be disputed. As higher-frequency data become more available and economical due to services being offered by many data vendors, it is hoped that future researchers could make use of order book data and investigate whether magnet effect exists, at what point it is most likely to trigger, the type of investors most prone to accelerate trading orders, and potential asymmetries.

\section{Conclusion}

Utilizing historical daily dataset of 150 active stocks (1994-2017) in Bursa Malaysia, a liberal exponent of price limits, we employ two benchmark logistic regression models and find statistically significant results suggestive of magnet effect for both upper and lower limits, though the evidence is weaker for lower limits. The findings also are consistent for three separate regimes spanning from 1994 to 2002, 2002 to 2013, and 2013 till now, with the middle period showing greatest conditional likelihood that prices fluctuate by the magnitude of price limit because of its very existence. The findings are consistent with earlier evidence presented by Bildik and Gulay (2006) from Borsa Istanbul; Chan et al. (2005) from KLSE, Cho et al. (2003) from Taiwan, and Xu et al. (2014) from Shanghai. The results suggest that price limits are not the boon as the Malaysian regulators tout them to be, and, in fact, exhibit self-defeating characteristics across all three regimes. 
JCMS

2,2

The regulators, thus, may want to consider experimenting with other magnitudes of limit or introduce multi-tiered limits based on price, industry, or capitalization, similar to London Stock Exchange.

\section{References}

Abad, D. and Pascual, R. (2007), "On the magnet effect of price limits", European Financial Management, Vol. 13 No. 5, pp. 833-852, doi: 10.1111/j.1468-036X.2007.00399.x.

Ackert, L.F., Church, B. and Jayaraman, N. (2001), "An experimental study of circuit breakers: the effects of mandated market closures and temporary halts on market behavior", Journal of Financial Markets, Vol. 4 No. 2, pp. 185-208, doi: 10.1016/S1386-4181(00)00020-3.

Arak, M. and Cook, R.E. (1997), "Do daily price limits act as magnets? The case of treasury bond futures", Journal of Financial Services Research, Vol. 12 No. 1, pp. 5-20, doi: 10.1023/ A:1007955909944.

Asmar, M. and Ahmad, Z. (2012), "Market microstructure and market liquidity: empirical evidence from Bursa Malaysia", The Conference on East Asia Finance, Tamkang University, Taipei, available at: https://staff-old.najah.edu/muath/academic-conference/smar-m-ahmad-z-2012market-microstructure-and-market-liquidity-empirical-0 (accessed January 29, 2017).

Avdis, E. (2016), "Information tradeoffs in dynamic financial markets", Journal of Financial Economics, Vol. 122 No. 3, pp. 568-584, doi: 10.1016/j.jfineco.2015.11.005.

Bildik, R. and Gulay, G. (2006), "Are price limits effective? Evidence from the Istanbul Stock Exchange”, Journal of Financial Research, Vol. 29 No. 3, pp. 383-403, doi: 10.1111/j.14756803.2006.00185.x.

Brennan, M.J. (1986), "A theory of price limits in futures markets", Journal of Financial Economics, Vol. 16 No. 2, pp. 213-233.

Chan, S., Huat, K.A.K. and Rhee, S.G. (2005), "Price limit performance: evidence from transactions data and the limit order book", Journal of Empirical Finance, Vol. 12 No. 2, pp. 269-290, doi: 10.1016/j. jempfin.2004.01.001.

Cho, D.D., Russell, J., Tiao, G.C. and Tsay, R. (2003), "The magnet effect of price limits: evidence from high-frequency data on Taiwan Stock Exchange", Journal of Empirical Finance, Vol. 10 No. 1, pp. 133-168, doi: 10.1016/S0927-5398(02)00024-5.

Dabbou, H. (2013), "Evaluating the widening of price limits: evidence from Tunisian Stock Exchange", Journal of Business Studies Quarterly, Vol. 4 No. 3, pp. 140-159.

Du, D., Liu, Q. and Rhee, S.G. (2009), "An analysis of the magnet effect under price limits”, International Review of Finance, Vol. 9 Nos 1/2, pp. 83-110, doi: 10.1111/j.1468-2443.2009.01086.x.

Fama, E. (1989), "Perspectives on October 1987, or, what did we learn from the crash?”, Issue No. 232 of Working Paper Series, University of Chicago, Center for Research in Security Prices, Chicago, IL.

Farag, H. (2013), "Price limit bands, asymmetric volatility and stock market anomalies: evidence from emerging markets”, Global Finance Journal, Vol. 24 No. 1, pp. 85-97, doi: 10.1016/j.gfj.2013.03.002.

George, T.J. and Hwang, C.-Y. (1995), "Transitory price changes and price-limit rules: evidence from the Tokyo Stock Exchange", The Journal of Financial and Quantitative Analysis, Vol. 30 No. 2, pp. 313, doi: 10.2307/2331123.

Hall, A.D. and Kofman, P. (2001), "Limits to linear price behavior: futures prices regulated by limits", Journal of Futures Markets, Vol. 21 No. 5, pp. 463-488, doi: 10.1002/fut.5.

Hautsch, N. and Horvath, A. (2018), "How effective are trading pauses?", Journal of Financial Economics, August, doi: 10.1016/j.jineco.2017.12.011.

Hsieh, P.-H., Kim, Y.H. and Yang, J.J. (2009), "The magnet effect of price limits: a logit approach", Journal of Empirical Finance, Vol. 16 No. 5, pp. 830-837, doi: 10.1016/j.jempfin.2009.06.002.

Huang, Y.-S., Fu, T.-W. and Ke, M.-C. (2001), "Daily price limits and stock price behavior: evidence from the Taiwan Stock Exchange", International Review of Economics \& Finance, Vol. 10 No. 3, pp. 263-288, doi: 10.1016/S1059-0560(00)00082-4. 
Kim, K.A. (2001), "Price limits and stock market volatility", Economics Letters, Vol. 71 No. 1, pp. 131-136. An investigation Kim, K.A. and Rhee, S.G. (1997), "Price limit performance: evidence from the Tokyo Stock Exchange", of magnet effect The Journal of Finance, Vol. 52 No. 2, pp. 885-901, doi: 10.1111/j.1540-6261.1997.tb04827.x.

Kyle, A.S. (1988), "Trading halts and price limits", Review of Futures Markets, Vol. 7 No. 3, pp. 426-434.

Lehmann, B.N. (1989), "Commentary: volatility, price resolution, and the effectiveness of price limits", in Lehmann, B.N. (Ed.), Regulatory Reform of Stock and Futures Markets, Springer Netherlands, Dordrecht, pp. 107-111, doi: 10.1007/978-94-009-2193-1_9.

Ma, C.K., Rao, R.P. and Sears, R.S. (1989), "Limit moves and price resolution: the case of the treasury bond futures market", Journal of Futures Markets, Vol. 9 No. 4, pp. 321-335, doi: 10.1002/ fut.3990090406.

Nath, P. (2005), “Are price limits always bad?”, Journal of Emerging Market Finance, Vol. 4 No. 3, pp. 281-313.

Sifat, I.M. and Mohamad, A. (2018a), "Circuit breakers as stability levers: a survey of research, praxis, and challenges", International Journal of Finance and Economics, doi: 10.1002/ijfe.1709.

Sifat, I.M. and Mohamad, A. (2018b), "Trading aggression when price limit hits are imminent: NARDL based intraday investigation of magnet effect", Journal of Behavioral and Experimental Finance, February, doi: 10.1016/j.jbef.2018.01.007.

Slezak, S.L. (1994), "A theory of the dynamics of security returns around market closures”, The Journal of Finance, Vol. 49 No. 4, pp. 1163-1211, doi: 10.1111/j.1540-6261.1994.tb02451.x.

Subrahmanyam, A. (1994), "Circuit breakers and market volatility: a theoretical perspective", The Journal of Finance, Vol. 49 No. 1, pp. 237-254, doi: 10.1111/j.1540-6261.1994.tb04427.x.

Subrahmanyam, A. (1995), "On rules versus discretion in procedures to halt trade", Journal of Economics and Business, Vol. 47 No. 1, pp. 1-16, doi: 10.1016/0148-6195(94)00020-E.

Subrahmanyam, A., (1997), "The ex ante effects of trade halting rules on informed trading strategies and market liquidity", Review of Financial Economics, Vol. 6 No. 1, pp. 1-14.

Tooma, E. (2011), "The magnetic attraction of price limits", International Journal of Business, Vol. 16 No. 1, pp. 1-13.

Wan, Y.-L., Xie, W.-J., Gu, G.-F., Jiang, Z.-Q., Chen, W., Xiong, X., Zhang, W. and Zhou, W.-X. (2015), "Statistical properties and pre-hit dynamics of price limit hits in the Chinese stock markets", PLOS ONE, Vol. 10 No. 4, pp. 1-20, doi: 10.1371/journal.pone.0120312.

Wong, K.M., Kong, X. and Li, M. (2016), "The magnet effect of circuit breakers and its interactions with price limits", SSRN Electronic Journal, doi: 10.2139/ssrn.2897328.

Wong, W.K., Chang, M.C. and Tu, A.H. (2009), "Are magnet effects caused by uninformed traders? Evidence from Taiwan Stock Exchange”, Pacific-Basin Finance Journal, Vol. 17 No. 1, pp. 28-40, doi: 10.1016/j.pacfin.2008.03.001.

Xu, H.-C., Zhang, W. and Liu, Y.-F. (2014), "Short-term market reaction after trading halts in Chinese stock market", Physica A: Statistical Mechanics and its Applications, Vol. 401 No. 1, pp. 103-111, doi: 10.1016/j.physa.2014.01.044.

Yang, D. and Zhang, Q. (2000), "Drift independent volatility estimation based on high, low, open, and close prices", The Journal of Business, Vol. 73 No. 3, pp. 477-492, doi: 10.1086/209650.

\section{Corresponding author}

Imtiaz Sifat can be contacted at: imtiaz@sifat.asia

For instructions on how to order reprints of this article, please visit our website:

www.emeraldgrouppublishing.com/licensing/reprints.htm

Or contact us for further details: permissions@emeraldinsight.com 